\title{
RADIOCARPAL FRACTURE DISLOCATIONS: A NEW CLASSIFICATION AND TREATMENT PROPOSAL
}

\author{
FRATURA-LUXAÇÃO RADIOCÁRPICA: NOVA CLASSIFICAÇÃO \\ E PROPOSTA DE TRATAMENTO
}

\author{
Emygdio José Leomil de Paula ${ }^{1}$ (1), Edgard de Novaes França Bisneto ${ }^{1}$ (1), Renata Gregório Paulos ${ }^{1}$ (1), \\ RAMES MATTAR JUNIOR ${ }^{1}$ (1)
}

1. Universidade de São Paulo, Hospital das Clínicas HCFMUSP, Faculdade de Medicina, Instituto de Ortopedia e Traumatologia, Hand and Microsurgery Group, São Paulo, SP, Brazil.

\begin{abstract}
Introduction: The radiographic and surgical findings, and treatment of radiocarpal fracture dislocations, were analyzed retrospectively in 40 patients. Materials and Methods: All patients were classified according to Dumontier's radiological classification and compared with the surgical findings. Based on this analysis, a new classification and treatment are proposed. Results: From 1995 to 2018, 40 patients with radiocarpal fracture dislocation underwent surgery. Thirty-six were males and four were females. The mean age was twenty-four years (range: 18-45). Three dislocations were volar dislocations and 37 were displaced dorsally. Initially, 8 (20\%) patients were classified as group I, $29(72.5 \%)$ as group II, and $3(7.5 \%)$ remained unclassified. The main variations occurred in group II. Seven fractures were stable after radial styloid fixation and 6 remained unstable. Sixteen fractures presented articular fragments or an interposed capsule, which prevented anatomical reduction using conservative maneuvers. Conclusion: Based in our intraoperative observations and surgical results, we believe that a more detailed classification should be adopted. Level of Evidence IV; Therapeutic Studies; Case Series.
\end{abstract}

Keywords: Carpal bones. Joint dislocations. Joint instability. Ligaments, articular. Radius fractures. Wrist injuries.

\section{RESUMO}

Introdução: Os achados radiográficos, cirúrgicos e o tratamento das fraturas-luxações radiocárpicas foram analisados retrospectivamente em 40 pacientes. Materiais e Métodos: Todos os pacientes foram classificados de acordo com a classificação radiológica de Dumontier e comparados com os achados cirúrgicos. Com base nessa análise, uma nova classificação e tratamento são propostos. Resultados: De 1995 a 2018, 40 pacientes com fratura-luxação radiocárpica foram submetidos à cirurgia. Trinta e seis eram homens e quatro mulheres. A média de idade foi de vinte e quatro anos (variação de 18 a 45). Três luxações eram volares e 37 dorsais. Inicialmente, $8(20 \%)$ pacientes foram classificados como Grupo I, 29 (72,5\%), como Grupo II e 3 (7,5\%), permaneceram sem classificação. As variações principais ocorreram no Grupo II. Sete fraturas permaneceram estáveis depois da fixação da estiloide radial e 6 permaneceram instáveis. Dezesseis fraturas apresentaram fragmentos articulares ou cápsula interposta que impediu a redução anatômica por manobras conservadoras. Conclusões: Com base em nossas observações intraoperatórias e nos resultados cirúrgicos, acreditamos que uma classificação mais detalhada deva ser adotada. Nível de evidência IV; Estudos Terapêuticos; Série de casos.

Descritores: Ossos do carpo. Luxações. Instabilidade articular. Ligamentos articulares. Fraturas do rádio. Lesões do punho.

Citation: Paula EJL, Bisneto ENF, Paulos RG, Junior RM. Radiocarpal fracture dislocations: a new classification and treatment proposal. Acta Ortop Bras. [online]. 2022;30(1): Page 1 of 4. Available from URL: http://www.scielo.br/aob.

\section{INTRODUCTION}

Radiocarpal fracture-dislocation is a complex injury characterized by dislocation of the radiocarpal joint, associated with avulsion of the dorsal or palmar cortical margin of the distal radius. Fractures of the radial and ulnar styloids are common. Reports in the literature vary widely from approximately 1 in 500 to 1 in 25 dislocations involving the wrist. ${ }^{1,2}$ This injury must, however, be differentiated from a shearing or rim fracture of the distal radius, in which the articular fracture is substantial and remains in contact with the carpus (Figure 1). ${ }^{3}$
Dorsal radiocarpal dislocations are more common than volar dislocations and account for $60 \%$ of cases. ${ }^{4}$ Historically, the prognosis of radiocarpal dislocation depends on the presence of intercarpal dislocations, and consequently, Moneim et al. ${ }^{5}$ proposed a classification based on it.

In a type I dislocation, the carpus remains intact, but tears of the radiocarpal ligaments cause the carpal bones to dislocate as one unit on the distal radius. In a type II dislocation, the ligaments connecting the carpal bones to one another are injured and therefore associated intercarpal dislocations are present (Table 1).

All authors declare no potential conflict of interest related to this article.

The study was conducted at the Instituto de Ortopedia e Traumatologia, Hospital das Clínicas HCFMUSP, Faculdade de Medicina, Universidade de São Paulo, São Paulo, SP, Brazil. Correspondence: Emygdio José Leomil de Paula. Ovídio Pires de Campos St., 333. Cerqueira César, São Paulo, SP, Brazil, 05403-010. leomildepaula@uol.com.br 
Lately, Dumontier et al. ${ }^{6}$ reviewed 27 radiocarpal dislocations and proposed a new classification. Group I dislocations include all patients with radiocarpal dislocations and possibly fractures of the tip of the radial styloid process. Group II dislocations include fractures of the radial styloid process that involve more than one-third the width of the radial scaphoid fossa (Table 2). The basis for the distinction is that in the first group the volar radiocarpal ligaments are torn from the radius and need to be surgically repaired to avoid ulnar/volar translation and in the Group II, this is not necessary. Also, this classification, does not discern between radiocarpal dislocations that also have associated interposed fragments and /or intercarpal dislocations. ${ }^{7,8}$ We performed a retrospective study of our cases and based on our observations, some modifications on Dumontier's Classification are proposed.

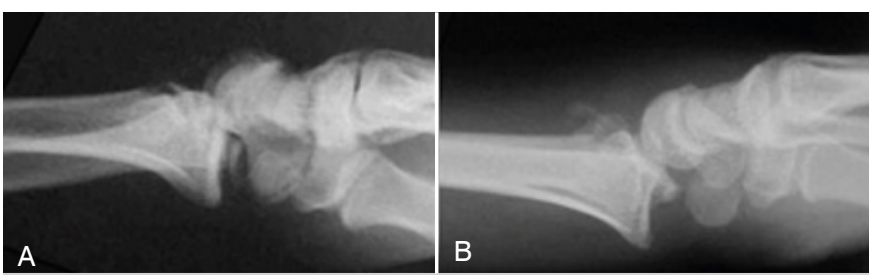

Figure 1. A) Radiocarpal Dislocation B) Shearing or rim fracture of the distal radius.

\begin{tabular}{c|c}
\multicolumn{2}{c}{ Table 1. Moneim's classification. } \\
\hline Type & $\begin{array}{c}\text { Radiocarpal fracture dislocation with fracture } \\
\text { of the radial or ulnar styloid or both }\end{array}$ \\
\hline Type I & $\begin{array}{c}\text { Radiocarpal fracture dislocation with fracture of the radial or } \\
\text { ulnar styloid or both, with associated ligamentary lesion. }\end{array}$ \\
\hline Type II &
\end{tabular}

\begin{tabular}{|c|c|}
\hline Type & Description \\
\hline Type I & $\begin{array}{l}\text { Pure radiocarpal dislocation or with only a fracture of the tip of the } \\
\text { radial styloid process. }\end{array}$ \\
\hline Type II & $\begin{array}{l}\text { Radiocarpal dislocation and an associated fracture } \\
\text { of the radial styloid process that involved more than } \\
\text { one-third of the width of the scaphoid fossa. }\end{array}$ \\
\hline
\end{tabular}

\section{MATERIALS AND METHODS}

A retrospective study of all radiocarpal fracture-dislocations referred to our service was performed. Age, gender and associated injuries were noted at the time of dislocation. Diagnosis of a radiocarpal fracture-dislocation was made on plain film injury radiographs and complementary CT scans when available. We postulated that type Il lesions, according to Dumontier's classification, presents severe volar ligament injury that must be repaired. All patients underwent surgery, and the operative findings were analyzed and compared with pre-operative images. Ethical approval for this study was obtained from Hospital das clínicas HCFMUSP, Faculdade de Medicina, Universidade de Sao Paulo, São Paulo, Sao Paulo, Brazil (approval number 4.283.317).

\section{RESULTS}

Forty patients presented with radiocarpal fracture dislocations were treated between 1995 and 2018. There were 36 male and four females. The mean age was 24 years (range 18-45). Twenty-seven were right wrists and thirteen left wrists. None had open injury. All patients were involved with a high energy trauma: 26 motorcycle accidents, 10 falls from heights, and 4 a car accident. Due to the violence of the event, we were not able to precise the mechanism of trauma and 26 patients presented associated injuries. The carpus was volary displaced in 3 patients.

Eight patients were graded as Group I (20\%); 29 as group II (72.5\%) and 3 unclassified (7.5\%). However, in the group II, only in seven patients (24\%), radiocarpal articulation remained stable after Radial styloid fixation and in 6 (21\%), presented instability even after fixation of the Radial Styloid. In this cases, extensive capsular rent was observed, and anterior repair was performed (Figure 2).

In 12 (41\%), interposed fragment of the anterior lip of the Radius, that were reduced and fixed with screws and four (14\%) anterior lip avulsion and dorsal compression fracture, that were reduced and fixed with screws or support plates dorsally (Figures 3 and 4). Three patients, with radiocarpal fracture- dislocation, with fracture of carpal bone and or intrinsic ligamentary lesion were observed (Figure 5).

\section{DISCUSSION}

Isolated radiocarpal dislocations are very rare; besides radiocarpal fracture dislocations are much more frequent, although both are uncommon injuries. ${ }^{1}$ In fact, this may be due to the low incidence
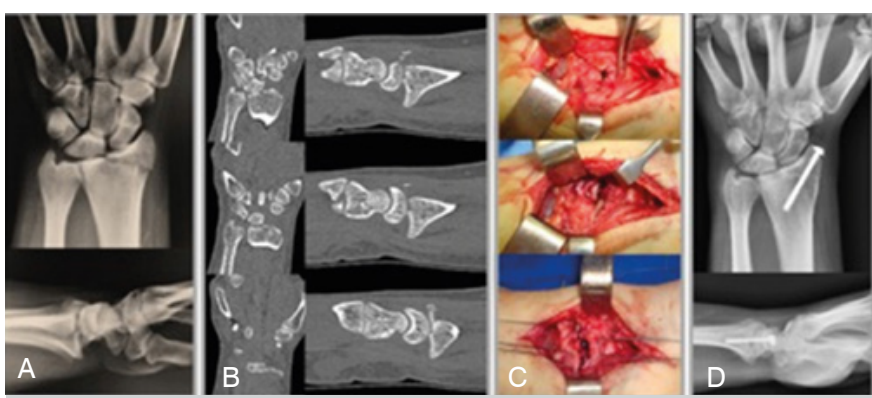

Figure 2. A) Dumontier's Type II, B) CT scans showing dorsal dislocations, C) Severe lesion of volar extrinsic ligaments and it's repair, D) Final radiographs.
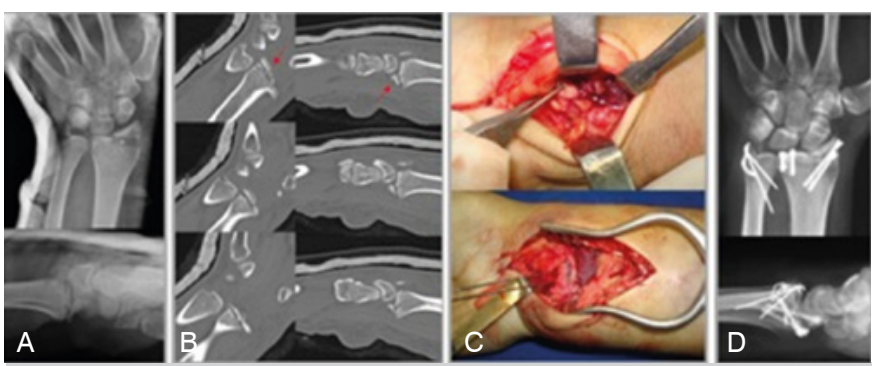

Figure 3. A) Dumontier's Type II, B) CT scans showing dorsal dislocations and large interposed volar fragment, C) volar rim of the radio rotated 1800 and it's temporary fixation after reduction, D) Final radiographs.
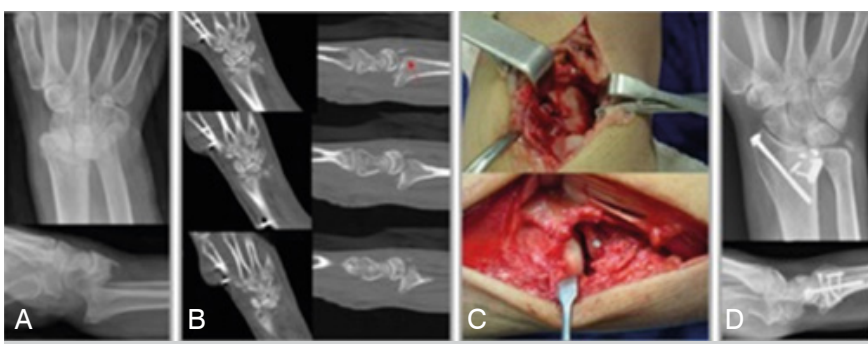

Figure 4. A) Dumontier's Type II, B) CT scans showing dorsal dislocations with major commitment of the dorsal rim of the radio, C) Severe lesion of volar extrinsic ligaments and fixation of the dorsal rim after reduction, D) Final radiographs. 


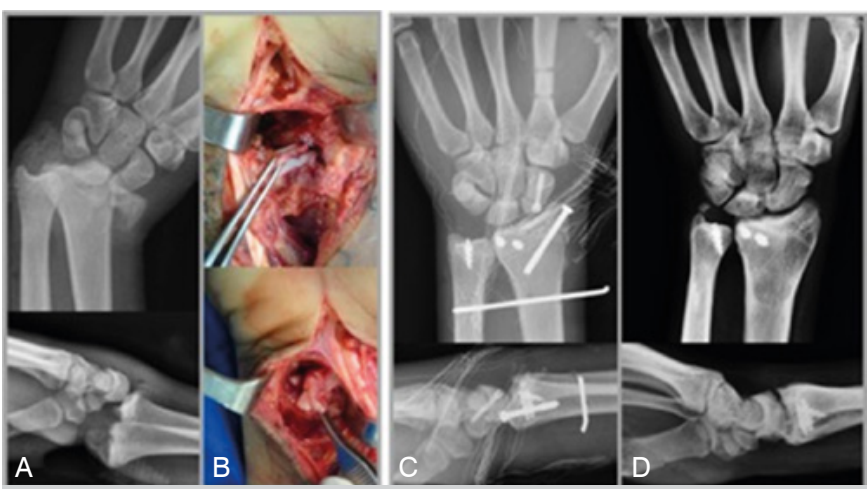

Figure 5. A) Unclassified radiocarpal dislocation, B) severe anterior capsular rent with associated FCT lesion, C) Immediate post reduction, D) Final radiographs.

of these lesions or because some authors include the radiocarpal fracture dislocations as a complex fracture in distal radius classifications. ${ }^{2,3,9}$ All patients in our series were involved in high energy trauma and associated lesions were frequent (65\%).

Regarding the mechanism of this injury, an association of hyperextension, ulnar deviation and hiperpronation. This rotational movement should be the cause of frequent commitment of the distal radioulnar joint presented in the acute phase or as sequelae. ${ }^{3,6,8}$ Graham ${ }^{10}$ described the pathomechanism of this injury in terms of transition forces that occur from lateral to medial aspect of the radius surface. He stated that pure ligamentary disruption seldom occurs, and these injuries are often associated by fracture of the radial styloid or at dorsal or volar margins. Two types of fracture patterns were described; a large fragment type and a small fragment type. The large radial styloid fracture runs obliquely from the area of the physeal scar near the crest separating the scaphoid and lunate fossa. This pattern, that in our understanding means a "traction fracture" was observed in 32 fractures of our patients. The small fragment type represents either avulsion by the stout extrinsic volar ligaments or impaction from the sub luxating carpus against the dorsal or volar margin of the radius. ${ }^{11,12}$ This study also suggested that the presence of ulnar-sided lesion is an indicative of more severe trauma. In our cases, despite absence of data, we didn't observe any case of pronation-supination impairment.

According with the adopted classification, in the group II, fixation of the Radial Styloid would be enough to stabilize the joint, because the volar ligaments remained attached in the radial styloid. ${ }^{8}$ However, in our data, in the 29 patients considered group II, only 7 (24\%) wrists remained stable after Radial Styloid fixation. The remaining, presented a great variance of presentation, when compared with intraoperative findings, ranging from anterior extensive capsule injuries to anterior marginal interposed avulsion radius fractures. Only in 4 dislocations, with major commitment of dorsal margin at lunate fossae were observed. These most common pattern, the ligamentary lesion or fracture at the anterior lunate fossae, explains the late ulnar translocation of the carpus, observed in many cases classified as group II by Girard et al..$^{13}$ and Lahtaoui et al. ${ }^{14}$

Lozano-Calderón et $a 1 .{ }^{15}$ include the radiocarpal fracture dislocations in a spectrum of what they call "dorsal articular margin of the distal part of the radius with dorsal radiocarpal subluxation" with four main characteristics: 1) Impaction of the majority of articular surface with relatively intact volar metaphyseal fracture line; 2) True radiocarpal fracture dislocation: lesion of radiolunate ligaments; 3) Radiocarpal fracture-dislocation with fracture of the volar portion of the Lunate facet where the radio-lunate ligaments originate; and 4) central articular impaction with relative sparing of the radial styloid and the volar most portion of Lunate facet. We did not observe in any of our cases impaction of the majority of articular surface or central impaction with sparing of radial styloid. The main characteristic of our cases was the occurrence of a volar lip fracture avulsion of the radius, generally at lunate fossa, in 12 patients (41\%). This characteristic has been mentioned, but not considered to determine another group, in the adopted classification or by other authors. ${ }^{16-18}$ In our understanding, the recognition and repair of the volar avulsion lip fracture is fundamental to maintain the stability of entire carpus and prevent any disability at distal radioulnar joint. The radiolunate and radioscapholunate ligaments are inserted at this site and this volar fragment, frequently, is also a part of distal radioulnar joint, that in our hands, it was impossible to achieve and maintain an anatomical reduction by close maneuvers or with isolated repair of the radial and ulnar styloids as cited by Mugdal et al. ${ }^{17}$ It's our opinion that in anterior lip fractures, surgical anterior fixation or ligaments reinsertion (with screws or bone anchors), prevents a chronic volar subluxation of the carpus and therefore, has a formal indication for anterior approach. As described by Bilos et al. ${ }^{19}$ and Schoenecker et al. ${ }^{20}$ the dorsal approach is necessary to reduce, under direct vision, the radial styloid or elevate impacted fragments that were dorsally dislocated. The posterior approach was our initial exposure in 3 patients to reduce carpal fractures or in patients with dorsally impacted fractures.

Based on these observations and our results, we propose a modification on Dumontier's classification, specifying the more common standards of the Radiocarpal dislocation and fracture dislocations. The group I, pure ligamentary lesion and associated with volar lip of the Radius. In this case the anterior approach extended to the carpal tunnel, allows a very good exposure of the entire anterior capsule retracting the Flexors mass and Median Nerve radially and ulnary thus enabling, an attack angle for screws fixation if it is necessary (Figure 6). In group II, Stable after reduction of the Radial Styloid. In this situation, the fixation of the radial styloid is enough. If it remains unstable or translated, anterior approach is indicated because the anterior lesion is extensive at the radioulnar joint. Anterior lip avulsion fracture, reduction and fixation of it predate reduction and fixation of the radial styloid. In our experience, after this, reduction the Radial styloid is very simple and easy. When dorsal compression fracture is associated, dorsal approach is needed first, to stabilize the radiocarpal articulation and then, anterior approach is performed to repair the volar lesion. In all this situations, definitive fixation of the Radial Styloid is performed by last. In cases that carpal commitment is present, dorsal approach is also performed first to reduce or repair fracture or ligamentary lesion (Table 3).

\section{CONCLUSION}

We believe that a good understanding based on a rationale classification could lead to a better treatment with an anatomical repair with stable fixation assuring satisfactory functional results.

Table 3. Proposed classification.

Type I: Radiocarpal Fracture dislocation without or a little commitment of the Radial and ulnar Styloid

A. Extrinsic Ligament lesion (Dumontier's Group I) B. Anterior Lip avulsion fracture

Type II: Associated with Transversal styloid radial fracture with volar or dorsal deviation

A. Extrinsic ligament lesion, stable after reduction (Dumontier's Group II) B. Unstable anterior lip avulsion fracture

C. Anterior lip avulsion.

D. Anterior lip avulsion fracture with dorsal compression fracture

Type III: Associated carpal lesion

Carpal bone Fracture / Intrinsic Ligament lesion 
AUTHORS' CONTRIBUTION: Each author contributed individually and significantly to the development of this article. EJLP conceived the study, researched literature, wrote the first draft of the manuscript protocol development, gaining ethical approval and data analysis. ENFB, RGP and RMJ jointly was involved with patient recruitment and data analysis. All authors reviewed and edited the manuscript and approved the final version of the manuscript.

\section{REFERENCES}

1. Dunn AW. Fractures and dislocations of the carpus. Surg Clin North Am. 1972;52(6):1513-38.

2. Pattee GA, Thompson $\mathrm{H}$. Anterior and posterior marginal fracture-dislocations of the distal radius. An analysis of the results of treatment. Clin Orthop Relat Res. 1988.231:183-95.

3. Fernandez DL, Ghillani R. Radiocarpal fracture-dislocation. In: Fernandez DL, Jupiter JB (Eds). Fractures of the distal radius. A practical approach to management. New York: Springer; 1996. 221-34.

4. Hardy P, Welby F, Stromboni M, Blin JL, Lortat-Jacob A, Benoit J. Wrist arthroscopy and dislocation of the radiocarpal joint without fracture. Arthroscopy. 1999.15(7):779-83

5. Moneim MS, Bolger JT, Omer GE. Radiocarpal dislocation--classification and rationale for management. Clin Orthop Relat Res. 1985.(192):199-209.

6. Dumontier C, Meyer zu Reckendorf G, Sautet A, Lenoble E, Saffar P, Allieu Y. Radiocarpal dislocations and fracture dislocations. In: Saffar P, Clooney WP (Eds). Fractures of the distal radius. Philadelphia: JB Lippincot. 1995. 267-78.

7. Bozentka DJ, Beredjiklian PK. Classification of radiocarpal dislocations and appropriate treatment. J Bone Joint Surg Am. 2001.83(10):1587-8.

8. Dumontier C, Meyer zu Reckendorf G, Sautet A, Lenoble E, Saffar P, Allieu Y Radiocarpal dislocations: classification and proposal for treatment. A review of twenty-seven cases. J Bone Joint Surg Am. 2001.83(2):212-8.

9. Fehring TK, Milek MA. Isolated volar dislocation of the radiocarpal joint. A case report. J Bone Joint Surg Am. 1984.66(3):464-6.

10. Graham TJ. The inferior arc injury: an addition to the family of complex carpal fracture-dislocation patterns. Am J Orthop (Belle Mead NJ). 2003. 32(9 Suppl):10-9.
11. Patel A, Wright WC, Wilson C, Augustine S, Griffiths HJ. Radiologic case study. Complete radiocarpal dislocation with an associated radial styloid fracture. Orthopedics. 2004. 27(6): 534, 625-7

12. De Paula EJL, Mattar R Jr, Rezende MR, Franca EN. Radiocarpal fracturedislocations: a study of 22 patients. J Hand Surg. 2011.36E(Suppl1):S105-18.

13. Girard J, Cassagnaud X, Maynou C, Bachour F, Prodhomme G, Mestdagh H. [Radiocarpal dislocation: twelve cases and a review of the literature]. Rev Chir Orthop Reparatrice Appar Mot. 2004.90(5):426-33.

14. Lahtaoui A, el Bardouni A, Ismael F, Jellali T, Bahri A, el Yaacoubi M, el Manouar M. [Posterior radiocarpal fracture-dislocation (eight case reports)]. Chir Main 2002.21(4):252-7.

15. Lozano-Calderón SA, Doornberg J, Ring D. Fractures of the dorsal articular margin of the distal part of the radius with dorsal radiocarpal subluxation. $J$ Bone Joint Surg Am. 2006.88(7):1486-93.

16. Loubignac F, Colomb F, Thiry A, Nasr Z, Lovet J. Isolated radiocarpal luxation. A case report and general review of the literature. Rev Chir Orthop Reparatrice Appar Mot. 1999.85(4):393-6.

17. Mudgal CS, Psenica J, Jupiter JB. Radiocarpal fracture-dislocation. J Hand Surg Br. 1999.24(1):92-8.

18. Biondi M, Lauri G. Dorsal fracture-dislocation of the radiocarpal joint: a new classification and implications in surgical treatment. $\mathrm{J}$ Hand Surg Eur Vol. 2020.45(7):700-8.

19. Bilos ZJ, Pankovich AM, Yelda S. Fracture-dislocation of the radiocarpal joint. J Bone Joint Surg Am. 1977.59(2):198-203.

20. Schoenecker PL, Gilula LA, Shively RA, Manske PR. Radiocarpal fracture--dislocation. Clin Orthop Relat Res. 1985. (197):237-44. 